\title{
1. The lost battle on truth
}

Post-factual politics, we read these days, is 'a form of politics where there is a willingness to issue warnings regardless of whether there is any real sense of the events being likely to come about ... or make claims that there is no real reason to believe are true' (Fish 2016). Post-factualism seems to reduce the question of truth to the question of power (Fuller 2017), because arguments concerning the need to understand the socio-historical contingency of truth-telling have turned ad absurdum to claims that anything can be true from a certain point of view. Post-factualism is praising emotions over facts (Higgins 2016), and has created a new era in which 'science is treated with suspicion and, sometimes, open contempt' (d'Ancona 2017). All these characteristics commonly suggest that there has been a reign of reason, that there was in the past a 'real sense of events'; that - in a nutshell - there was a world in that we simply knew what truth was and in which it was clear who held that truth.

However, truth is a battle. In science, it has always been a battle of cultural patterns, institutional path-dependencies and coalitions of actors who needed to be convinced to look at the evidence in front of them and to acknowledge the truth in the light of that new evidence. In that way, truth has been the main interest of the investigation of the social interdependence of 'facts' and 'expertise' that has been produced by the scholarship of critical approaches to policy studies and science and technology studies. These approaches have shown that social problems and scientific discoveries are contested and debated on the basis of whether or not they are believed to be true, and by whom they are debated. While looking at these debates and contestations, these approaches have disclosed that truth is socio-politically coproduced, linked to public concerns and political consequences (Jasanoff and Simmet 2017), and linked to institutions that deploy strategies to defend and perform truth, so that they can support their policies and policy instruments with legitimate knowledge.

The analysis of post-factual politics therefore needs to shift the focus from 'the truth' toward the analysis of these rules of the battle over truth, the truth's scenography. For most of the modern times, these rules have coined the notion of truth as fact-based knowledge, objective and neutral, coming from scientists or experts. The lenses of scenography open a 
gateway to problematize and analyse this cultural ascendency of scientific knowledge in politics through the defence of scientific truth manifested across scientists' protests against the Trump administration in the United States (US), and against science denial in general. The cultural ascendency of scientific knowledge has sustained modern government's legitimacy by being used as evidence to support political actions, and to let them appear as 'rational' or even 'good'. By doing so, the cultural ascendency succeeds in hiding behind 'facts' and 'scientific practices', its value-loaded patterns of thinking and its culturally charged ways of arguing. As part of this process, it has excluded emotions from its presentations and discussions. And it succeeded in holding the sceptre of truth, even if it was sometimes terribly wrong. It is thus necessary to look behind the veil of the cultural ascendency of scientific knowledge and analyse its scenography, in order to be able to observe how truth is negotiated with and against emotions, and how this negotiation is not related to post-factual times but has become a by-product of the establishment of modern science and modern democracy.

\section{IT IS ABOUT GETTING TO THE TRUTH: ${ }^{1}$ INTERPRETING THE CULTURE OF POST-FACTUAL POLITICS}

We are living through very puzzling times. Times where the unexpected, the counter-intuitive, and the irrational makes headlines day after day. (Euroscientist 20 February 2017)

This quotation represents a pointed summary of the first weeks after Trump first occupied the Oval Office as it was portrayed by the members of scientific community. Although the March for Science orchestrated the highpoint of protests against the claimed attack on scientists, on facts and on truth by the Trump administration, the mood had already started to take the concrete shape of protests back in November 2016. Immediately after Donald Trump's election on 8 November as the 45th President of the United States, scientists across the US made explicit their fears about the decline of science together with a decline in democracy. The Union of Concerned Scientists (UCS) circulated an open letter to the presidentelect and to the incoming Congress with the aim to protect science. The American Geophysical Union's annual meeting organized a 'Stand Up for Science' rally. Stand up for Science became both a slogan mobilizing scholars from various disciplines and various career ranks to express their fears over science's future standing, as well as a rallying call for those 
horrified by the news in the first weeks of the presidency, when the new administration - holding the rest of the nation hostage - resolutely started down an anti-science and anti-truth path, as it had threatened to do. The fear was that science would lose, and that it would lose not only funding, but also the public respect and the basis upon which to act to make US society healthier and better; to make it 'great', as many of them paraphrased Trump's emotionally evocative election slogan in their discussions around the public role of science. Concerns such as these were continuously articulated by non-profit initiatives and researcher groups and then commented on in the press, in scientists' blogs and during academic gatherings. The principal argument voicing this fear was supposed to go beyond the usual differences among scientific disciplines, approaches and school of thoughts (as discussed by Frickel 2018; MacKendrick 2017; Brulle 2018); it was also supposed to go beyond ideology, and beyond a cultural divide between Republican and Democratic voters. To protect science from attacks on truth, facts and scientific expertise were employed to emphasize that 'facts' and 'the objective truth' were in danger when facing a president who lies repeatedly and without compunction, who does not correct previously articulated inaccuracies, and who even repeats these inaccuracies while laughing. A president who is the first in 75 years to fail to appoint a science advisor during his first year. As one of the main organizers of the March for Science told a radio reporter, the protest by the scientists, therefore, 'is about getting to the truth' (CHRO 13 February 2017).

This atmosphere in the aftermath of Donald Trump's election was the context for the emergence of the Harvard University blog First 100 Days, aiming to track and reflect the 100 days after Trump's inauguration in January 2017 from the perspective of the role of science in democracies, and for democracies. The blog had already been advertised before the end of 2016, presenting itself as a collective platform to describe and analyse the new era predicted to arrive with the Trump administration, and inviting researchers beyond Harvard to join in discussion of the events. This new era was thereby expected to be stretched between what the authors of the blog framed as 'normalization' and 'disruption', the two keywords being also used by several journalists to describe the new style of the Oval Office. Trump's disruption went, in these descriptions, beyond the values he and his administration announced they would defend after he was elected, and then after he took office. Trump was characterized as disruptive in the public discourse criticizing his politics because he would not rely on the expertise that was already there, but instead appointed people who either had no background in the matters which they were to manage (the most prominent examples being Trump's daughter Ivanka and his son-in-law Jared Kushner) or seemed to be equipped with more of 
a celebrity background, misusing science for public entertainment (such as the appointment of the celebrity physician Mehmet $\mathrm{Oz}$ as the head of the Council on Sports, Fitness, and Nutrition; VOX 4 May 20182). Trump was seen as disruptive because he would not comply with the known institutional standards of negotiating and decision-making, or the usual pathdependencies, but deleted agendas, announced changes without knowing the context of what related changes these were embedded in, or issued executive orders without consulting the related offices beforehand in order to pre-empt eventual legal inaccuracies and challenges. The travel ban in Executive Order 13769, which created waves of protest around the country, was seen as a measure against immigration that was too severe, and intended to hurt many immigrants who had been successfully integrated in the country's society and economy; it was seen as an attack on the nation's diversity and tradition of successful immigration. The executive order was also criticized in the light of the information that the Justice Department was not consulted on the matter beforehand. This critique was supported by the circumstances that the executive order was released less than two weeks after Trump took office. Similarly, Trump's announced changes to Obamacare during the first 100 days was jeopardized by Trump's claim that he was not aware that health care reform would be 'that complex'.

That President Trump seems to be, in general, 'not aware' became the underlying argument for many to argue that the disruption caused by his administration is threatening US governing and US democracy. Criticizing him and his appointees from the perspective of fact-checking, and emphasizing that these people are ignorant of scientific expertise or misusing it to make bold statements without checking the facts, has become the essential line of this argumentation. Related to that, journalists and, increasingly, scientists started to highlight that the president openly appoints deniers of science to leadership positions in US administrative bodies of scientific expertise, mostly in the area of climate change. The appointment of wellknown climate change denier Scott Pruitt as head of the Environmental Protection Agency (EPA), which then began to limit the media coverage of its actions and to censor some of its own reports and activities, was the most conspicuous step of the Trump administration that also concentrated many scientists around the Silencing Science Tracker, which had been created after Donald Trump's election by the Sabin Center for Climate Change Law, and the Climate Science Legal Defense Fund as a non-profit watchdog of these changes.

The Silencing Science Tracker (SST) started to track any action at any level of the US government that showed traces of government censorship, self-censorship, budget cuts, personnel changes, research hindrance, and bias and misinterpretation of published research, mostly in the area of 
climate change but also in other science areas, especially in public health. In just a year it had collected 133 reports on such activities that it made available to journalists, educators and politicians collecting information about the marginalization of science in US politics (SST 8 February 2018). The first signs of the need for such tracking were that Trump weakened federal advisory committees, that he appointed conflicted individuals to scientific leadership positions, mostly tied to industries falling under the jurisdiction of the agency or department, or that he left these positions vacant. Specifically, the administration initiated the weakening of science-based pollution standards without any scientific justification, and public access to data has been reduced. Together with restrictions on communications between Congress and scientists, all these steps have created a hostile environment for scientists. The 'Science not Silence' slogan was prominently used by the marchers later that year, and although there has not been any direct link between the march organizers and the providers of the tracker, 'silencing science' has been echoed in both of them as a metaphor to visualize this new disruptive atmosphere.

Facing all these disruptions, the 'normalization' within Trump times the term chosen by the Harvard blog, First 100 Days - was, on the one hand, represented in the media discourse by a wish to get back to the usual path-dependencies of the chief US executive. The critique of the Trump administration would also bring Republican (Grand Old Party, GOP) voices critical of newly proposed plans, thereby emphasizing that the conflict is not about values or ideological divides but about a lack of expert path-dependency that goes beyond the limits of political conflicts. In a nutshell, Trump was seen as being outside the range of 'normal'. On the other hand, fear was apparent in many of these argumentations that Trump's disruptive culture of unawareness and impulsive governing would become the new normal. This was the most represented focus of the texts that appeared in the First 100 Days blog. The blog succeeded in assembling some of the most prominent scholars in STS, the majority of whom were based at Harvard University itself. The core of the blog argumentation is timely for scholars linking their work on science to the public cause of discussing the Trump presidency. Through this link, the claimed attack on truth has been materialized as a showplace for the long-held concern of STS scholarship about democracy and politics.

Concerns over the role of science in democracy and politics, such as those discussed on the First 100 Days blog, have an intellectual history within the scientific community of the US East Coast universities, generally seen as liberal and involved in political debates (Harvard debate 2016). These university communities share the history of some other protests by scientists, among them the Union of Concerned Scientists' call 
for action in the late 1960s. In December 1968, a group of engineers from MIT reacted to the political situation at that time. Signed by 50 senior scientists, their public statement contested US involvement in the Vietnam War and asked that research resources be directed away from military research toward social and environmental problems. The major impetus was not only the atmosphere of social protests occurring throughout 1968 around US military involvement, as well as around minority rights, but also the heavily polluted air and waterways across the nation; indeed, six months later, the heavily polluted Cuyahoga River, which runs through Cleveland, caught fire, capturing the nation's attention about pollution. These circumstances portrayed for the MIT scientists that the United States faces other, and more important, challenges that it needs to solve, with and through science. To take action in supporting the public cause of science then became the primary purpose of the group, formed in early 1969 and now known as the Union of Concerned Scientists. The Union had stood up for fact-checking, and for defending research budgets, and so it was expected that the Union would endorse the activities around the 2017 March for Science.

The ties to civil society and political decisions made by the scientists in the aftermath of 1968 and its echoes create an important context to understand the cultural divide that we now observe as a consequence of the advent of the Trump presidency, and that is now framed predominantly by the belief or disbelief in science. As Mabel Berezin shows in her cultural analysis of Trump's electorate, the identity of Trump supporters goes as far back as these socio-political circumstances of the debate on Vietnam War and surrounding civil protests (Berezin 2017). In her analysis, Berezin goes beyond the discussion about the conflict and retrieves the set of narratives forming the academic culture of protesting; the protester were seen then by those who were drafted or who wanted to go to the war as a privileged or even arrogant group that protested instead of fighting in the war, and that could afford this thanks to their socio-cultural status. Berezin suggests that these historical narratives were part of a larger socio-cultural divide playing with the anti-expertise discourses during the 2016 presidential election, because this gave new and fresh impulse to the divide between an intellectual elite engaged in academic discussions, and the everyday experiences of people who have been despised by many of these intellectuals as hateful people who would support bad political decisions. A similar socio-cultural divide is outlined by Arlie Hochschild, who aims to situate the larger historical path-dependencies that make Americans push back on liberal values and support science denial. Hochschild paints a picture of a divided nation on the basis of the distinction between the lived experience of 'ordinary' US citizens who have been working hard, and the elite who 
might be knowledgeable but are detached from these deep experiences with 'ordinary life' (Hochschild 2016).

The scholarly discussion around the advent of the Trump administration reflects that evoking the divide between privileged and non-privileged Americans (Hayes 2013) creates an 'epistemic challenge' (term used by Archon Fung in Harvard debate 2016) to achieving mutual understanding. The polarization of the United States makes it harder to establish knowledge as legitimate, as many note when commenting on Trump's presidency (Mansbridge 2018a, 2018b). But those engaged in the scholarly discussion want to get across the understanding that the United States faces an entirely different situation with the advent of the Trump era. Americans need to understand this. As the Center for Science and Democracy (CSD) holds, this situation is 'altering the day-to-day lives of Americans' (CSD Report, p. 5). Loaded language was deployed to paraphrase semi-catastrophic narration, such as 'side-lining Science since Day one [sic]' (CSD Report), and the wording specifically evoked disintegration, such as 'eroding the ability of science'. This time, things are worse than ever before:

All modern presidents, to some extent, have politicized science and compromised scientific integrity. At times, presidents and their affiliates have falsified, fabricated, or suppressed evidence, selectively and deceptively edited documents, exaggerated uncertainty, tampered with scientific procedures, allowed conflicts of interest to interfere with decision-making, let political considerations drive advisory board appointments, and intimidated, censored, and coerced scientists. (Center for Science and Democracy report, p. 5)

And so came the idea of a March for Science, on the social platform Reddit, which is outside the usual networks of civil protests in US science advocacy, marshalling within three days more than 1.5 million supporters. The first major impetus to organize a March for Science was caused by significant science budget cuts announced by the Trump administration shortly after he took office in early 2017 . Not only were the specific figures and the affected programs considered problematic, but also the way these were embedded in the context of the open and explicit denial of truth was worrisome. The Trump administration's insistence that the media inaccurately reported the crowd size at the inauguration was followed by the administration ridiculing the well-established press as promulgating 'fake news'. ${ }^{3}$ All of this echoed the administration's disregard for the widely accepted scientific consensus of the anthropogenic cause of climate change, manifested for example by the deletion of the climate change agenda from the White House website immediately after Trump took office, as well as by the jarring appointment of a climate change denier to head the EPA. Four days after taking office, Trump signed an executive 
order to revive the Keystone XL pipeline, which had been previously rejected by the Obama administration on the grounds of exacerbating climate change. He also signed an action to help Energy Transfer Partners complete its Dakota Access Pipeline in North Dakota. But perhaps most worrisome during this period was President Trump's signing on $28 \mathrm{March}$ 2017 of a wide-ranging executive order that rolled back the Obama administration's efforts to combat climate change, especially the key mechanism by which the United States was intending to meet the emissions cuts it had committed to under the 2015 Paris Agreement. ${ }^{4}$ The repeated denials of the anthropogenic causes of climate change from the presidential office convinced scientists of the urgent necessity to act, recognizing the Trump administration's growing trend to sideline scientific expertise (as also reported continuously by the SST).

Some of these events were not necessarily new in US politics: the Nixon administration had also attacked the media, and the Republican Party's rejection of scientific evidence, in particular the denial of anthropogenic causes of climate change, represents a larger and longer-term phenomenon (see, e.g., Gauchat 2015; Mooney and Kirshenbaum 2009; Nisbet and Mooney 2009). But the timing of these events and the vehemence with which any critique was dismissed by the Trump administration as 'fake news', along with the general populist mood across Western liberal democracies, made the situation unbearable for many scientists, motivating them to take action and thus to endorse the march. This was indirectly supported by many initiatives beyond the field of science: in the US context, the proliferation of truth-finders and media fact-checkers, including the ongoing campaigns of the New York Times ('The truth') and the Washington Post ('Democracy dies in darkness'), and the Washington Post's Fact Checker site. ${ }^{5}$

The mode of protesting the Trump administration's disregard for truth and science was concretized by the second impetus: ${ }^{6}$ the Women's March in Washington, DC, and elsewhere around the world, on 22 January 2017. This march united feminist activists with citizens previously inactive in feminist protests to organize and participate in what was to date the largest global feminist protest in modern history. Immediately after the Women's March, Caroline Weinberg and Jonathan Berman, the main organizers of the March for Science, met through the Reddit social platform and joined forces when they realized they both had the idea of a march of scientists. The third main organizer, Valorie Aquino, joined later, with social media platforms providing the means to expand the idea, quickly leading to the organization of more than 600 marches around the world. Through both the event and the bottom-up way of organizing it, the March for Science became inscribed into the long tradition of non-violent civil protests, 
in which dissatisfied citizens have taken to the streets to protest against government policies and to demonstrate their strength to the governing elites. Media reflections in the run-up to 22 April frequently referenced figures such as Martin Luther King Jr and John Lewis from the Bloody Sunday March in Selma, Alabama, making the connection to civil protests and social movements more apparent.

Events, as these, created together a necessity for scientists to proclaim and to embody that 'science fights back'. As one scientist said on MSNBC when questioned about Donald Trump's science denial, 'he is going to deny, he's going defund and that means that a disaster is now possible' (MSNBC 2017). What eventually looked to some as an overestimated rage by the end of 2016 was increased during the following year by the attack on the use of language by US research and public health organizations; the most prominent example being the Center for Disease Control and Prevention (CDC) being banned from using such terms as 'science-based' and 'transgender' (see Figure 0.1 in the Introduction). I discuss the role of this juxtaposition in Chapters 3 and 4, but here it is important to stress the circumstances that make 'science' and the 'scientific' a cultural cum political stance that needs to be either suppressed, or endorsed: that facts matter, climate change is real and science is a public good that can and should be supported by civil society. The March for Science made visible that the protest for science, analysed below, was simultaneously a protest in favour of the culturally ascendant position of science, which makes innovation and societal progress its ultimate goal. As put by one of the most prominent supporters of the March for Science Neil de Grasse Tyson: 'The real cleavage, in other words, isn't between those who believe in God and those who don't, but between those who want to change the world and those who just want to repeat it' (De Grasse Tyson 201677).

'Getting so bad even the introverts are here' read one of the posters at the New York March for Science on 22 April 2017. This joking awareness of the stereotype of scientists as nerds who do not like to talk to people, particularly strangers on the street, articulated well the awkwardness that I felt in the air before, during and after the march. It felt incongruous to see people in their lab coats, so alien to protesting that they were uncertain whether and how to shout their slogans. It was jarring, a bit surreal, that scientists, who customarily prepare posters for academic sessions to show their latest work were now carrying posters of different kind: protest posters, where their role was not as professional scientists but as activist citizens proclaiming their values and stakes. In some cases, you could not be sure whether these posters - with a prominent logo of their labs - were dedicated to an academic poster session where scholars show their newest work, or whether they were demonstration posters where active citizens 
showed claims, values and stakes. Or did these marchers actually want to make the statement that their scientific facts are their stakes?

Some of them did indeed want to make this point, which is why they deliberately linked the March for Science with Earth Day. Many posters stated that their carriers 'March with her', using coloured pictures of the Earth. With the focus on Earth and on anthropogenic cause of climate change, many marchers also underlined one of the prominent impetuses of this march: the systematic sidelining of scientific expertise concerning climate change, let alone the banning of the use of the word 'climate change' in policy documents in some US states (as reported by the Silencing Science Tracker), as well as censorship on many administrative levels concerning references to the anthropogenic cause of climate change. Most of all, these stakes were calling scientists to take action against continued appointments of climate change deniers to high positions (for example, Scott Pruitt to head the EPA in February 2017, which marked for many the moment to act); to take action using and through scientific facts, such as 'There is no Planet B'. Many marchers referenced threatened animals in order to make their stakes more tangible, for example marching 'For polar bears', carrying with them plush velvet polar bears or dressing as polar bears, bees, and other species in danger (the Dakota pipeline was also referenced).

Major scientific achievements in the 20th century were referenced as arguments that science needs to be trusted, funded and supported, with most scientists citing the success of vaccination - for example, 'Vaccines work' or 'Got a polio? Me neither cause science works' - thereby linking the denial of the scientific evidence of vaccination to Donald Trump's campaign claim parroting a link between vaccination and autism. This thesis represents a prominently discussed story of a science denial going back to the late 1990s, praising the British doctor Andrew Wakefield for his thesis that mumps-measles-rubella (MMR) vaccines cause autism. I will outline the details of Wakefield's story in Chapter 2, but here it is important to stress that to hear the claim from the presidential candidate, and then later from the office of the president, made this thesis for many scientists an even more serious threat to US society, and to the future prospects of science development and science funding. Many posters therefore used the anti-vaccination claim to mark their support of the March for Science: 'Science saves lives', 'Science saved my life', you could read in many colours and in many fonts not only in New York, but also at other big march rallies in Washington, DC, Boston and Los Angeles. Other posters enumerated the usual props of modern Western society, almost self-evidently present in our everyday lives: smartphones and the internet; but also penicillin, contact lenses, water purification and GPS: 'Thank you science!' 
The third set of stakes was related explicitly to science funding. In this context, scientists taking to the streets presented yet another group demanding their rights. With slogans such as 'Fund brains not bombs' and 'Less invasions more equations', marchers created the binary opposition of science and war. A similar binary opposition was established along the lines of slogans such as 'Build labs not walls', which referred to Trump's promise to his supporters to build a wall along the Mexican border. These binary oppositions at the same time played into the larger binary of the factuality posing rationality, knowledgeability and sobriety against disorder, irrationality and even caprice. Some signs were explicit and referred to funding as a platform where those governing decide what to support, and should thus decide on the basis of this factuality: 'Hey Congress, don't understand it? Don't defund it!! Ask! Learn!!' Some of the posters personified this critique by referring to Trump's physical attributes. His constant fidgeting, and joking references to his 'tiny hands', were added to references in the US media to Trump's alleged ignorance, narcissistic behaviour, narrow-mindedness and irrationality, to strengthen the critique: 'Funding: keep your tiny hands off my pipettes'. The highlights of the demonstrations regarding the Trump administration's capriciousness were those related to climate change. Marchers dressed as boats and icebergs, and staged floods and ice melting as they marched. One person, dressed up as Trump, stood next to the marching crowd, waving to marchers passing by. She repeatedly swung a golf club at a ball painted as the Earth; she waved the golf club around, mimicking Trump's distinctive and well-known movements and gestures, then looked around, checking that everybody was watching, before leaning again towards the ball, but never hitting it (Figure 1.1).

However, the argument for funding went beyond the usual conflict over distribution of public finances: the very essence of 'truth' and 'rationality' - and not the financing itself - was the stake of the marchers. 'Make America think again', was for example written on a simple card that a woman held in her hands while walking fast through Central Park toward the meeting point of the march in New York. She was a scientist herself, she told me. Elevating the visibility of the argumentation to the level of the whole US society, which needs scientific expertise and which needs facts and truth, was a widely represented goal among the marching scientists: we must 'Make America smart again' and 'Make America scientific again' because 'America needs science' (Figure 1.2). The observation that science is one of the precious public goods and that it deserves a support of every single citizen' was featured by the video of the Boston march rally (Boston 2017). That science equals progress and that those who ignore science ignore future generations was a supporting narrative of this argument: 


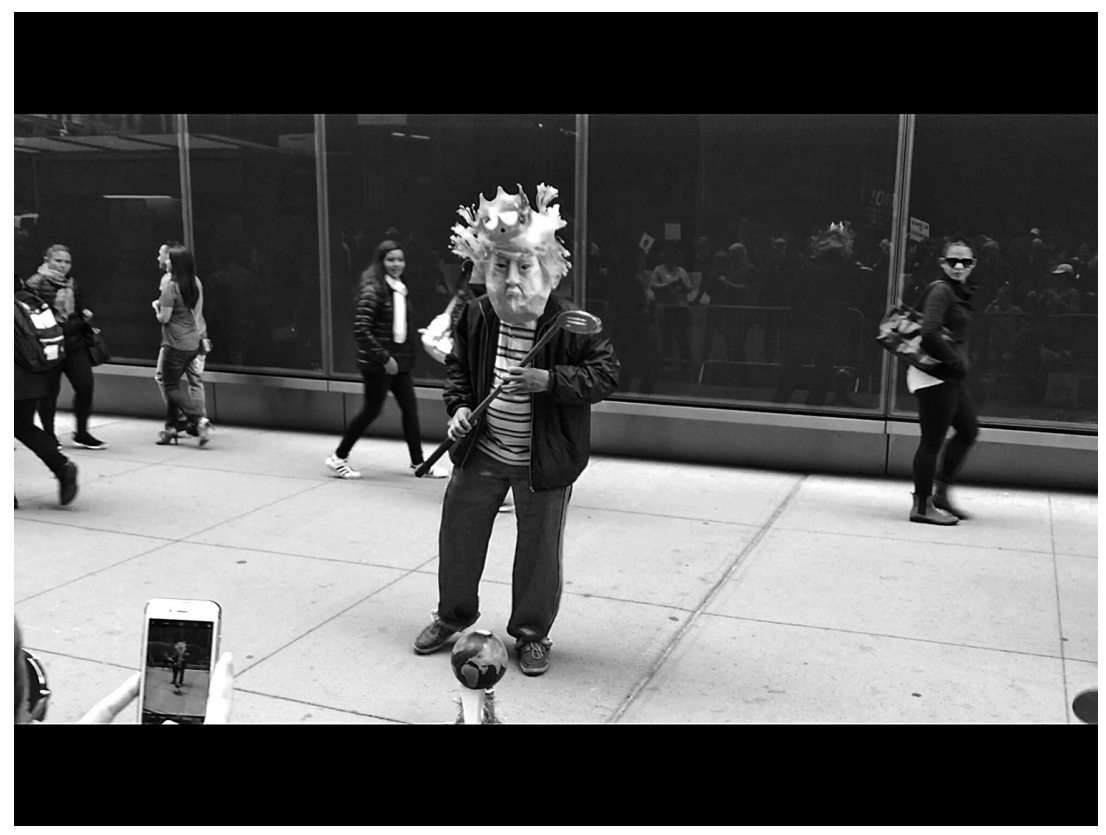

Figure 1.1 Screenshot from video of a demonstrator during the March for Science in New York City, dressed as Donald Trump

Science is, and should be, the 'engine of prosperity' (Spectrum 02/14/17). Slogans such as these had a greater goal than praising the reasonability and rationality of science: they framed science as a civic value, as something that 'bonds us together'. As one scientist wrote during the preparation of the march, 'I am marching in the common interest of all Americans' (Spectrum 02/14/17). We are 'Smarter together' some wrote on their posters; thus, it would be logical that 'Strong science [means] strong America'.

Anti-scientist behaviour would subsequently be portrayed as antidemocratic, because good science needs good democracy, as many professional associations also argued in support of the march. Many texts and interviews with scientists published during the preparation of the march emphasized this causal link, highlighting that science flourishes only in democracies. 'The United States has proven that both science and democracy are the most effective systems we've developed to organize, understand and improve our world' (WashPost 8 February 2017). Does science really do that automatically and unconditionally? I wondered, as I read these posters in the streets of New York and reflected on their claims, set against the history of scientific programmes in nuclear research 


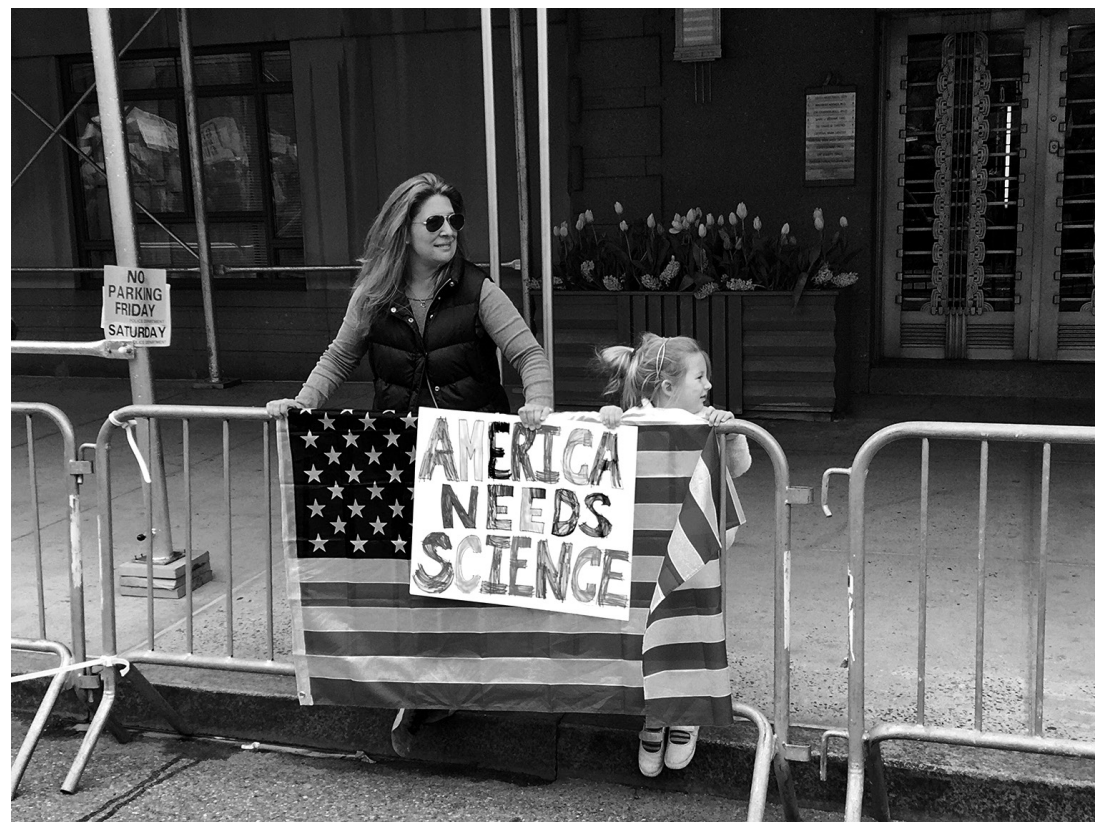

Figure 1.2 Poster of the New York City march rally, 'America needs science'

in some of the anti-democratic countries that seemed to advance not only despite the lack of democracy but, one could argue, because of it. How to frame, for example, the continuous threat that the Soviet Union represented toward the US moon landing or the National Aeronautics and Space Administration (NASA) mission? However, reading the posters, observing the atmosphere and reading the media coverage, I felt that the March for Science was univocal about this: science needs autonomy, and 'truth is freedom'. Stakes as high as these echoed scientists' terrified reactions to Donald Trump's recurrent science denial. The video produced from the Boston Rally of the March for Science cited the prominent STS scholar Sheila Jasanoff as saying that 'this movement is about the quality of our democracy and the quality of science in it' (Boston 2017); because 'To abandon facts is to abandon freedom', as one could read on another poster, also from the same Boston rally.

All these references to truth and knowledge, although powerfully summarizing actual threats to US science as performed by governmental officials, seemed not to paint a complete picture. Something was missing here; a somewhat refined notion of truth would be needed to understand the event, to make it understandable beyond the scientists gathered around 
the truth they all share and know. 'Truth is not a partisan issue' was frequently used as a slogan by the marchers, and it felt right and pertinent in the context of an era of US politics where lies are presented by public relations (PR) people as 'alternative facts', and where scientific evidence is misinterpreted, either deliberately or out of ignorance. This assault on truth seemed indeed to be part of a systematic roll-back of scientific progress and societal progress, launched by Trump's administration. Many academics started to discuss the advent of a new era characterized by raging against enlightenment (Alexander 2019), as if US society was on its way back to 'pre-Enlightenment times', as Sheila Jasanoff described during the Boston march rally.

However, there remained an ambiguity in all these powerful statements. 'Climate change is not a debate. Vaccines are not a debate', said for example by Richard Ebright from Harvard Medical School at the Boston march rally. Although he marked the moment of the Trump administration's assault on science and the sidelining of scientific evidence related to both vaccination and climate change, in fact all scientific facts underwent debate before they were accepted. The debate - either directly through panels and discussions in academic gathering, or indirectly through peer review - is intrinsic to the identity of science. Debates make science solid and less erroneous and, in that sense, finally more accepted. So why would we deny or downplay that aspect?

Or is that debate only for scientists? Debates make science controversial and an object of distrust for many, which is why the public understanding of science approach insists that scientific knowledge is put through societal analysis. Given these reflections, the marchers' arguments that science is real, and that it is true whether you believe in it or not, represented more than just stakes in support of US science. To believe in reason, and in science, amounted to an identity mark. This identity mark created an image of marchers as 'fact-based people raising their voices' (Alligator 14 February 2017). 'Fact-based' refers to cultural values praising reason and knowledge and inviting distrust of emotions and gut-led intuitions. By using a range of references to 'facts' and by opposing reason to belief, these posters introduced an argumentative posture that to defend truth means, in that context, to defend a culture that praises rationality; for example, one of the signs in New York proclaimed ' $\pi$ is all the irrationality I need'.

The march thus created oppositions and powerful references, through which it seemed that what is in the air is the ambiguity residing in the identity of those nerdy scientists who do not know how to shout in the streets but who feel an urgent need to do so, because the jobs they love and are so passionate about are in danger. These scientists became protesters because their mission to guide societies is in danger. They have emotional 
stakes, although their identity as scientists creates an awkward moment when they feel compelled to proclaim those stakes. One text depicted the struggle pertinently in the narration of 'Why I'd rather not march' (NPR 13 February 2017). The narration portrayed the ambiguity as an awkward moment of a scientist not wanting to mingle with politics but having no other choice than to do so, due to the exceptional events in 2017. As another one argued, 'Scientists can no longer hide in their labs' (Peekskill Daily 13 February 17). Moreover, scientists joining the march and arguing for the necessity of joining the movement felt an urgent need to act against the assault on truth, because they feel responsible for societal developments and want to do something to stop what they see as a potential disaster: 'At the beginning of every catastrophic movie, there is a scientist being ignored' read a poster in Boston that was reprinted by several media outlets reporting on the march, and that pointedly marked the mission felt by many. So, it is scientists' civic duty to fight back not only because they have the privilege of understanding this world, but also because they have a duty to act in the name of that privilege to protect their fellow citizens. 'It has never been more important for scientists of all stripes to come together and have their voices heard in government', stated one of the first tweets of the March for Science (@sciencemarch 25 January 2017).

However, it was still unclear how this mission should be passed to the public, especially to those who on many occasions had expressed their negative opinions of scientists, and did not want to listen to these 'nerds' and 'arrogant superiors'. Some marchers thus emphasized inclusion of and dialogue with the public: 'Ask me about my research' was a recurrently used imperative, or the tweet with a photo of a woman: 'Don't believe in climate change? Ask an Earth Scientist (I'm right here)'. Similarly, posters proclaiming such things as 'This is what a scientist looks like' portrayed scientists as inclusive people who want to communicate with the public. This was also stressed by the organizers of the march, 'This is not about creating divides. It is about the public', Caroline Weinberg said during a radio interview (CHRO 13 February 2017), highlighting on that occasion that 'you don't need to be a scientist to understand science is important' (THE 13 February 17). One concrete way to articulate the proximity to the public was the active involvement of Bill Nye the Science Guy, who was appointed by the march organizers to the communication committee as one of its three representatives, along with two scientists. Bill Nye is a person that most Americans associate with science communication, although he is not a scientist.

Creating awareness of the need for science implied at the same time creating public support for science. Some argued the public's involvement and expertise are necessary to proceed with scientific inquiry: 'Diversity and inclusion make science better'. This dimension was reinforced by 
events to enhance public awareness of science, such as teach-ins during the marches and the organization of the 'Kids March for Science' rally, which accompanied the March for Science in Washington, DC. The involvement of children in demonstrations around the march used the cliche of childhood dreams to give an affirmative image of science, such as 'Forget princess. I want to be a scientist' (displayed on Buzzfeed 22 April 2017). Some used the involvement of children and high school students to stage the march as 'a unique opportunity to communicate the importance, value and beauty of science' (04/07/17/AAAS). An intrinsic part of this strategy was to highlight the march as a gathering of 'lovers of science' (02/22/17/ Kgou) without referring to other social movements, let alone the context of being just another political demonstration against Trump. In this respect, the aim of march was to publicly communicate science as 'key to human freedom and prosperity' (Mail Tribune 4 April 2017).

Through references and codes such as these, the marchers for science were identified by their support of factuality, which consequently excluded politics'. This binary subsequently implied a range of other related binary oppositions: the positive image of science, its beauty presented in an overall positive event embracing children's dreams, is opposed to a political demonstration of scientists wanting their rights (back). The rationality of science, its 'facts' and equations, are opposed to 'denial', 'fear' and, most importantly, 'politics'. Signs reading 'Believe in science not in politics', and variations on that theme, appeared frequently at the marches, indicating that science does not lie and does not deny. The underlying message was that politicians lie, particularly Trump, as for example in this paraphrasing: 'Mr President go fact yourself'.

At the same time, although politics was not supposed to mingle with science, political references were a prominent part of the slogans - 'Grab a lab coat not a pussy', 'Make America scientific again' and 'Science not silence' - indicating that scientists are a sizeable group that should not be invisible to those running this country. This referenced the announced and then real budget cuts of science funding, and the censorship of language available to the CDC. In the same respect, scientists participated in the march in order to show that the criticisms of scientists had gone too far. While before the Trump era it was clearly a case of scientists making the input and then values being discussed in politics, "now they call science a hoax and the problem is that they seem to deny the very existence of scientific knowledge' (NPR 13 February 2017). But the march was intended to remain a pro-science event and not turn into an anti-Trump event.

Through its symbols, rhetorical devices and references the event of the march shows that while the collective defence of truth is being staged as unifying science and democracy and making this a common and pressing 
interest for all Americans, the performance of this defence of truth through the march reveals the same cultural divide that the march initially wanted to challenge with that protest. Being a scientist, being above society, in order to be able to make predictions, was associated with superiority and arrogance. The belief in reason and rationality was praised by the marchers to such an extent that the critical and reflexive capacities of science seemed to be excluded. In that way, the success of science as portrayed in the posters on scientific achievements, and as supported during discussions of the culture of expertise, is usually based on what Western society labels the 'rationality' of experts (Traïni 2015; Memmi 1999; Centemeri 2015; Fassin 2017) which is under attack by the Trump administration. This has been further reinforced by other sources of moral outrage for scientists, beyond the march: the advent of post-truth, and the divisions and political polarization over expertise: 'Scientists and philosophers should be shocked by the idea of post-truth, and they should speak up when scientific findings are ignored by those in power or treated as mere matters of faith' (Higgins 2016).

Through its manifold demonstration of rationality, objectivity and neutrality, as opposed to the emotional moods of the unscientific president and the emotionalized, misinformed public, the March for Science has unveiled a paradox of the modern debate on the rules of the battle on truth. On the one hand, we have been told that facts are without emotional appeals. Scientists across disciplines agree that it makes sense to a certain extent to hold this line within scientific inquiry, because only in that way can scientific discoveries break with values and beliefs, if on the basis of the new knowledge they see the need to do so. Scientists need to switch off the emotional background linked to these values and beliefs, they need to listen to the data and to the evidence, to be able to deliver the truth. On the other hand, this line of argument incorporated scientific expertise into the Western paradigm as a solely rational, deliberately non-emotional and in that sense a value-free enterprise, and thus discussion on socio-political interdependence of truth production is caught in the binary of factual knowledge and emotions. I explain the importance of this binary in the next section, relying on one of the most prominent examples of a scientist being too emotional to be able to get his facts accepted. His story will help me to problematize the relationship of science and politics to emotions.

\section{SEMMELWEIS'S LESSON FOR THE BINARY OF FACTUAL KNOWLEDGE AND EMOTIONS}

The example of Ignaz Philipp Semmelweis, obstetrician and pioneer of medical hand hygiene, is a perfect example to show how the sceptre 
of truth is being recurrently challenged and even subverted by new discoveries, and how emotional appeals take a substantial part in this process although they have been downplayed in the public discourse on science. The essence of this public discourse is what I call here the binary of factual knowledge and emotions. In February 1849, the letter from the director of the Vienna General Hospital holds a clear rejection message of the efforts of obstetrician Ignaz Philip Semmelweis, citing 'well-being of the hospital' as a reason for his decision, despite the fact that Semmelweis devoted his career at the hospital to an ambitious and desirable goal to put an end to the rising mortality rates of women from 'childbed fever', a disease that afflicted many women giving birth in all European hospitals at that time. Childbed fever was assumed to be the reason why the wording of the decision not to prolong his contract was fairly ambivalent. Whereas Viennese obstetricians, together with Semmelweis's supervisor Johann Klein, criticized Semmelweis for being harmful to the obstetrics department, the first of two gynaecology departments in the hospital, with the second being the department of midwifery, and forced him out, the British obstetrician Charles Routh had reported on the 'Viennese success' to the British Medical Association and travelled to Vienna to see how Semmelweis had accomplished the happy and almost unexpected reduction in the number of mothers dying from childbed fever.

The controversy started back in May 1847, when Ignaz Semmelweis made what became a problematic discovery for his colleagues and for accepted medical practice of the day: that the reason for childbed fever lay not in the physiological conditions of the mothers, or in the course of childbirth, but in doctors' hands. Semmelweis, and indeed the entire European medical community, was troubled by the recurrent advent of a strange epidemic of childbed fever. Childbed fever was a monster of 19 th-century obstetrics, threatening this new branch of the medical profession that embraced childbirth as its key competence. All across Europe, obstetricians in hospitals were affected by epidemics of childbed fever at least once a year. Young, healthy women suddenly succumbed to this fever and found death in the hands of the doctors instead of help. The earliest epidemics had already been registered in France between 1662 and 1664; in the 18th century we find reports from London; in 1770 and 1771 an epidemic was recorded in Dublin and also in Vienna. But the 19th century was the high point of this disease: rumours circulated in Vienna that giving birth to a child at the obstetrics department was dangerous; you would never come out once you entered that department. You were considered lucky to instead find yourself in the midwives' department, where the chances for survival were much higher. 
Semmelweis's discovery supported these rumours with a concrete explanation, thus creating a serious threat to the reputation of Viennese obstetrics and obstetrics in general, which had been only recently established as a distinguished discipline aimed precisely at improving birth care. By situating the origin of childbed fever in doctors' hands, Semmelweis's discovery implied the responsibility of professional obstetrics for the disease outbreaks. To accept that doctors' hands transmitted the disease meant accepting responsibility for the past epidemics of childbed fever. Mothers were dying, newborns were dying, and the doctors did nothing. The doctors of the Vienna General Hospital, the largest hospital in Europe with 6000 births per year, could do nothing when hundreds of these women were dying of childbed fever in the hospital. Semmelweis strongly reproached his Viennese colleagues, who opposed his proposed measure, with these facts, and in doing so he probably strengthened their feelings of responsibility and guilt.

All this was obviously damaging Vienna's dominant position in European health provision, which went back to the 18th century when the Vienna General Hospital was founded and developed into one of the most prominent hospitals in Europe. As in other major cities in Europe during this time, Vienna also dealt with the problem of providing health care to the general population, especially the poor. Of particular interest to our reconstruction of the Semmelweis controversy is the situation of poor and unmarried women, who often gave birth under miserable circumstances, despised by society. The administration of Emperor Joseph II saw insufficient health care of the poor as a threat to the state. A healthy general population had been considered an important factor in productivity since the Enlightenment, so hospital care was increasing - but so was childbed fever. 'To born a child is as dangerous as the Lung infection of the first degree,' Semmelweis wrote in 1846 when describing his terrifying and anxiety-producing experience with the disease (Semmelweis 1905).

Within this context, Semmelweis discovery was also damaging to the scientific reputation of Viennese medical expertise, as it implied that the rise of an extensive pathological practice at the General Hospital, albeit bringing fundamental improvements in Viennese diagnostic methods and bringing world fame to the hospital, was a crucial factor in the recurrent disease outbreaks. Carl von Rokitansky, a contemporary and teacher of Semmelweis, believed that pathology as a scientific discipline should be in the service of the hospital. He therefore integrated the pathological practice more thoroughly into the education and training of doctors in order to help them understand diseases better and explain their development. Rokitansky's ambition was to identify as precisely as possible the causes of diseases. The role of pathology was associated with the hope of 
being able to use the regular practice of autopsies to systematically investigate physiological processes in the body. And not only that: it had become common practice that every clinic performed autopsies on all patients who died within its walls. Obstetricians were also to gain a better understanding of the processes and complications of childbirth by systematically examining corpses every morning, before moving on to seeing mothers awaiting or just after childbirth. That was how these autopsies produced further disease outbreaks: the hands of medical professionals inadvertently transmitted the bacteria and miniscule tissue of corpses inside birthing women, infecting them with 'childbed fever'.

Semmelweis's discovery thus turned the everyday practices of the hospital upside down. While the rumours of increased risk of death surrounding the obstetrics department of the Vienna General Hospital, compared to the department of midwifery, were making the doctors uncomfortable, their actions against childbed fever were consistent with other obstetrics practices in all large European hospitals of that time. Several theories surrounded the cause of childbed fever, which were seen as well established, and these made sense under the circumstances of the time. The milk fever theory was linked to the relatively low awareness of the physiological processes of female bodies at the time (Olshausen and Veit 1899; Lumpe 1843, 1845). Childbed fever patients usually had some form of lactation disorder, and many doctors saw this as the origin of the high fever. The French doctor Nicolas Puzos believed, for example, that the milk would transfer from the breasts to the body cavities (Dumont 1989). He posited that the body stopped working, deviating from its usual physiological processes. This offered a logical explanation for the infection in all organs of the body, as usually revealed in autopsies, and so were also the conclusion reached by the Parisian medical staff at the prestigious Hôtel-Dieu hospital in 1746 that CB spreads through the miasma (which I discuss more in the next paragraph), where childbed fever epidemics occurred several times. Related to that, several moods of women were associated with fever pathology: there was an assumption that young women felt ashamed to be examined by the young male doctors, or that they felt guilty for being unmarried and banned by their families. Another hypothesis was linked to the exertion of the uterus during pregnancy, caused by physical work during pregnancy.

By far the most dominant theory, and a paradigmatic one during that time, was the miasmatic theory. Miasma was a cosmic-telluric condition in the air, which, in simple terms, included certain air conditions and could also collect pathogens. In Vienna, an inspection was ordered to examine the outbreaks of childbed fever and to explain their cause. Its conclusion confirmed the paradigmatic explanation that childbed fever resides in the 
air. All big hospitals in Europe had a long list of hygienic measure to clean the air and aerate the rooms; the epidemics would occur once the miasma became full of contamination, but once the air was 'purified' with incense, the epidemics would cease, according to the theory. There was not much to do about it, just waiting: that is what everybody said, and did. Nobody suspected a wrong connection here. It made sense to everyone, and so the theory was integrated into the everyday knowledge and practice. The disease was associated exclusively with pregnancy, was seen as a disease of strained mothers, and the epidemic outbreaks were seen as due to the influences of the miasmatic conditions. The considerations of the doctors seemed logical. Practically every sick woman could not breastfeed, almost all had worked during pregnancy, or they were under the stress of an illegitimate pregnancy, because only women from the lower classes gave birth at large hospitals; anyone who could afford a family doctor gave birth at home.

One detail was, nevertheless, particularly disturbing in Vienna: the hospital had two departments alongside each other. The midwifery department was doing better, so women were trying to be admitted there, and not to the doctors. That was the reason why Semmelweis was bothered and wanted to understand what was actually making the difference in death rates. Although the two departments worked together without any problems and nothing indicated a conflict (Lesky 1964; Benedek 1983), the difference their daily practices was important for the events that followed. For more than a year, he screened doctors' practices and compared them to those of midwives. He noticed that his department had a much higher mortality rate (11.4 per cent) than the department of midwifery ( 2.79 per cent), and found that the divergence of the mortality rates coincided with Semmelweis's superior, Johann Klein's decision to separate midwives from doctors. Klein changed the practice of autopsies in the obstetrics department, back in 1840 . He did so in the spirit of the then-current Viennese zeitgeist in respect of autopsies, and to strengthen the role of pathology in the hospital. Related to that, the obstetrics department employed only doctors and medical students, while the midwives had their own department, where a chief physician worked, but no medical students were trained except those devoted to midwifery.

Semmelweis therefore did not accept the inspection conclusion that this disease resided in the air and that the differences between the two departments would be related to two miasmas separated by the walls. His observations brought him closer to the fact that childbed fever was somehow related to doctors, although he did not know exactly how. Historical sources often indicate that a substantial factor in his discovery was the sudden death of his former colleague, the pathologist Jakob Kolletschka, 
who injured his finger during an autopsy. His autopsy report was similar to those of the young mothers. Semmelweis also discovered during the autopsies he was regularly doing that autopsy report of mothers who died of childbed fever resembled those of their deceased newborns, which conflicted with the assumption that this was a female disease related to birth and pregnancy. So Semmelweis started to pay attention to the role of everyday practices of the doctors in the obstetrics department in the disease outbreak. As midwives were not performing any autopsies, Semmelweis subsequently hypothesized that his hands - the smell he could identify after each and every autopsy, the smell on his hands of the corpse - were the cause of childbed fever. He could not identify this smell further, but he ordered his physician colleagues to disinfect their hands with a chlorinated lime solution until the smell was gone, before attending childbirth. And death rates declined rapidly.

We now know that Semmelweis was right about the origin of childbed fever, and hand hygiene has since become the cornerstone measure against the spread of diseases (Flamm and Aspöck 1999; Pittet and Boyce 2001). Semmelweis held the truth despite the rejection of his colleagues. So, why did almost nobody believe the young Viennese doctor back in the second half of the 19th century? Why did he, instead, become an object of derision and contempt for what was seen as his insult to the medical profession? His thesis that whatever soiled the doctors' hands was responsible for the deaths was not accepted, even three decades after his death. Although some obstetricians admired Semmelweis's endeavour and introduced sanitary measures that Semmelweis proposed for doctors' hands - disinfection in a chloral solution before each examination, and before each birth - these were exceptions. Most obstetricians considered Semmelweis's writings about the hygienic procedure to be nonsense, reproaching him for his lack of evidence, as he could not tell what exactly on the hands should cause childbed fever. Some even suspected that Semmelweis was obsessed with denigrating obstetrics. The Viennese hospital accused him of wanting to denounce the hospital through his childbed fever reports. Although fewer mothers died after his intervention, as proven by the childbed fever reports, those in his professional environment did not respond to it by changing the practice. They did not even want to try to change it. It seemed as if they wanted to get rid of not Semmelweis, but his discovery. ${ }^{8}$

Most historians working on the scientist have a logical explanation for Semmelweis's failure: his emotionality was to blame. Based on correspondence and archives, they suggest that the rejection of his discovery came from his situation: Semmelweis was very unpopular among his colleagues, among them especially his supervisor Johann Klein. In historical sources, the director of the obstetrics department Johann Klein is often 
portrayed as a malevolent arch-enemy of Semmelweis, who blocked the medical progress out of fear of the then Austrian Chancellor Metternich (Silló-Seidl 1978, 1985; Nuland 2006). We can neither confirm nor refute this assessment here, but it is interesting to see that societal mood of that time is being qualified by the historical analysis of scientific dispute as interfering in the pursuit of scientific evidence, which goes against the usual stereotype of scientific practice as being beyond such emotionality. In particular, the fear of a superior scientist deserves attention, for it shows that emotionality eventually resided on both sides of the Semmelweis story. Klein's fear might be read as 'cautiousness' - against radical explanations that could be far-fetched - which would be reinforced by the recurrent emphasis in historical sources on Semmelweis's unstable personality. Semmelweis's personality would have made it difficult to take him seriously (Nuland 2006). Some even suggest a pathological character to his temper (Benedek 1983), supported by the fact that Semmelweis died in an asylum. We know from historical sources that Semmelweis, indeed, imprudently called his opponents 'murderers', 'medical Nero[s]' and 'dumb Turks' (Semmelweis 1861, 1905). But who would not eventually feel anger and frustration if - after numerous observations - a measure that actually seems to work, simply will not be even tried or tested?

To support the role of emotionality in Semmelweis's failure, analyses from science theory offered their versions of non-rational actions intervening in the scientific controversy around his discovery. Those analyses explain the rejection of the discovery by citing strategic errors Semmelweis committed with respect to scientific practices. Some analyses point to the mistake that Semmelweis did not use a microscope and therefore could not see the germs on doctors' hands (Carter 1985). He did not use a microscope because Rokitansky's concept of systematic autopsies was to a large extent against the practice of using microscopes, which allows works in the theory of science to make the argument that the scientific environment of Semmelweis's time was particularly inconvenient for his discovery to find success in the scientific community of the time. The other prominently cited reason of the failure is that Semmelweis failed to publish his results until ten years after his discovery (Lesky 1964). Some even now hold that his work is 'unreadable', and consider this to be an adequate explanation for the conflict (Loudon 2005). Would earlier publication of the results have been less harmful for the doctors of obstetrics? Would publication have induced less conflict over acceptance than the discovery? Would better language be less threatening to the Viennese reputation? It seems not: although these strategic errors and personal animosities might have had an effect on the dissemination and the popularity of the theory, they insufficiently explain the failure on the whole. 
Most importantly, while this story seems to have a happy ending, for Semmelweis entered the modern history of medicine as the pioneer of hospital hygiene and evidence-based medicine (Rangappa 2010; Durnová 2015a), and on this account we have found the truth about childbed fever and about hand hygiene, it leaves a question mark over the future prospects of the relation between science and societal moods and anxieties. What if there is a Semmelweis of our times, who we despise as irrational and unscientific because what they say is harmful and threatening either to our everyday lives or to our governing elites? The rationality of science, which seemed to lead us through scientific uncertainty to reveal the path of truth, becomes more complicated. As much as the established practices and responsibilities secure stability - much needed in the provision of care of the population in this case - they can become oppressive for new discoveries.

Reading the Semmelweis case through the lenses of scenography of truth shows that his discovery was embedded in a range of such societal practices and responsibilities; and that to break with them was simply threatening and involved emotions on both sides of the story. The emotionality did not eventually reside only in Semmelweis's personality, and it was not a problematic surplus of his discovery: it was the very core of his discovery. His discovery was not problematic because of any sort of internal or external validity, and it was not problematic because he could not show the germs on doctors' hands. His discovery was at odds with the whole system of that time because it was 'vexatious knowledge'. A brief look into other examples in the history of science suggest, furthermore, that such a situation is not specific to Semmelweis's case, because every truth is at odds with the knowledge we have accommodated and believed to be true. This is also why Robert Anton Wilson has found inspiration in Semmelweis's failure by referring to the general unwillingness to change the everyday understanding of phenomena surrounding us as a 'Semmelweis Reflex' (see also in Balint and Balint 2009; Henderson et al. 2018).

At the same time, to stress the emotionality of the discovery, and not that of his personality, opens a path to sheer away from the conflictual logics through which the case is usually portrayed: as a fight between two groups - supporters and deniers of Semmelweis - who take sides based on path-dependencies, historical and political contexts, or the context of their enemies. One frequently referenced consequence of such conflictual logics is that Semmelweis is now celebrated as the hero of midwives. Criticizing obstetrics makes him the defender of midwives' cause, although midwives have never been his primary concern or the main focus of his argumentation. Framing the story as a conflict between two sides assumes that there could be some purified version of Semmelweis's knowledge about childbed 
fever, a non-partisan and a neutral version, which would allow the conflict over hand hygiene to be avoided. But Semmelweis's knowledge created partisanship, which is why it has been eventually classified by some as partisan: his knowledge did not capitalize on the oppositions, but it created them because it equipped them with new knowledge.

Through these two aspects - the vexatious knowledge and its consequent partisanship - Semmelweis offers a blueprint to understand post-factual politics and the current reactions to it. His case challenges the view of scientific discoveries as something outside and beyond emotional animosities and collective societal moods. Throughout historical analyses of the Semmelweis case, we see the portrayal of a division between rational and non-rational action that is supposed to guide us through the scientific inquiry and show us the path of truth. The view that emotional appeals are disrupting the rational pursuit of facts, that they might cause scientists to deviate from objective and neutral inquiry, is the essence of this path. This path has sustained the binary of factual knowledge and emotions that makes science culturally ascendant, something superior to everyday wisdom and local knowledge, something uniting the rationality of expertise beyond culture, beyond ideology and beyond emotional appeals. To investigate this binary further and to outline its consequences for democratic governments might therefore help in understanding how post-factual politics operates.

\section{CHALLENGING THE CULTURAL ASCENDENCY OF SCIENTIFIC KNOWLEDGE}

The narrations of scientific figures, such as Semmelweis, provide examples of the cultural ascendency of scientific knowledge, which has been an inherent part of the establishment of modern politics based on science and expertise. Although scholarship on socio-political interdependence of scientific knowledge has highlighted that science does coproduce values and does shape public interests, highlighting the role of emotions in this interdependence enables us to understand how public debates on science mediate values and beliefs through emotional appeals. Paying attention to particular discursive registers of emotions that coproduce a cultural ascendency of scientific knowledge helps us to understand how the cultural ascendency of scientific knowledge simultaneously and implicitly qualifies the unscientific, the vilified; and in that way sustains the dichotomy between factual and emotional when science is used as a source of expertise in politics. The negotiation of scientific evidence in modern politics - albeit accepting that values and beliefs of the society play a part 
in establishing the truth - has sustained this dichotomy because it refers to 'professional norms', 'standards' and 'conventions', and thus ignores how these norms and standards might be produced with and through the emotional contexts in which the knowledge is being debated:

If there is no demonstrative certainty for the conclusions of science, their 'truth', or at any rate their acceptability as scientific results, can only be established by convention: through a consensus of experts in the field and the fulfilment of certain methodological and professional norms - the rules of the scientific game. (Majone 1989, 43)

In his central work on modern policy-making, Giandomenico Majone subscribes to the negotiation of truth, which is the first part of the lesson that Semmelweis's story teaches us. Majone set forth a robust scholarly path in policy analysis, which concentrated the analytical investigation on how the consensus of experts comes into being and how this is coproduced through both scientific facts and the values the experts propound or contest. Majone called for institutionalizing the debate around these questions in a new approach to public policies. He saw policy analysts as those craftsmen, who - if trained properly - would be able to set up such institutionalization, because by foregrounding what he treated as the argumentative part of evidence, data and information would form persuasive grounds for subsequent political actions.

The idea of institutionalizing persuasion has spurred numerous ways to address argumentation and the presentation of evidence and knowledge in politics (Fischer and Forester 1993; Fischer 2009b; Gottweis 2006; Hajer and Wagenaar 2003; Hajer 2005a; Stone 2002; Griggs and Howarth 2011, 2016; Torgerson 1985). The common ground of these approaches has been that policy-makers need a consensus in order to proceed. Yet this consensus is negotiated, and these negotiations involve institutionally, culturally and historically accepted professional norms as much as they count on the individually acquired 'social skills' of the negotiating actors (see Majone $1989,4)$. Related to that, the call for a 'reflexive knowledge' (Lasswell 1971; Torgerson 1985, 2013, 2017) further reinforced the necessity of taking into account the boundary between individual capacities of the analyst to persuade, and the institutional socio-political, historical and cultural boundaries within which they construct this persuasion.

The boundary of personal (individual) and institutional dimensions of knowledge has also been addressed by other approaches to knowledge-making, mainly in political sociology (Weber 1926; Nash 2009; Stehr 1994), sociology of scientific knowledge (Stehr and Grundmann 2005; Moore et al. 2011; Frickel et al. 2010; Frickel and Moore 2006) and, more recently, critical policy studies focused on expertise (Strassheim 
2017, 2015; Strassheim and Kettunen 2014; Torgerson 2017; Fischer and Gottweis 2012; Hajer 2009; Voß and Freeman 2016). Deborah Stone refers in this respect to 'clinical authority' (Stone 1993), which creates a cultural authority of expertise and science in modern governance through quantification, measurement, promise of objectivity and scientific expertise (ibid., 48). Through such authority, the boundary of the individual and the institutional creates the agency for knowledge because it defines for individuals what is normal, acceptable and logical; in short, what is true.

For all these approaches, truth develops into an important asset of social power because it creates standards and divides societies into supporters and enemies of such standards. Truth is the fact-based knowledge that defines problems as such, and gives reasons and arguments for legitimizing collective actions and standardized procedures. We know from larger theoretical investigations of politics that while truth has not always been seen as a virtue for the everyday practice of politicians and political institutions (Kellner 2007; Arendt 1972; Forester 1981; Torgerson 2013, 2017), it has always created a factual reference point for political actions, which is the background which social and political analysis has been interested in, particularly social and historical contexts of truth-telling (Norval 1999; Douglas 1966). Also, studies of larger societal transformations influenced by lying (Pasquerella and Killilea 2005), and analyses of the role of the establishment of fake identities for everyday politics (Keyes 2004), have advanced social and cultural explanations of both the importance and the fragility of truth in politics (Bucciol and Zarri 2013; Zerilli 2012).

The specific focus on truth in policy expertise applied here is thus centred around the particular language means through which knowledge is presented as fact-based and is argued to be a sound basis upon which to proceed with political action. In such a focus, emphasis is mainly put on the discursive interdependence of truth, in which truth is coproduced by power relations and the institutional background, while simultaneously producing them. Such an understanding of the fact-based knowledge produced within discourse has become part of a large and diversified orientation toward the role of language in policy processes, recently coined as 'critical policy studies' (Fischer et al. 2015). To understand the discursive interdependence - nowadays essential to any critical stream in policy inquiry - we find the epistemological foundation in the Foucaldian notion of truth. Foucault conceives power as a dimension that is developed through particular disputes and conflicts over practices. Through his figure of 'the will to know', Foucault shows that power is organized through the negotiation of practices, and that these negotiations have a discursive nature (Foucault 1966, 1969b, 1971, 1976b, 1984, 2008). In this way, Foucault's approach shows 
how discourse establishes political order, thereby producing 'truth', which is why the use of discourse to explain political change and political order puts emphasis on his thought (Gottweis 1998, 2003; Hajer 1993; Torfing 2005; Howarth 2010; Brass 2000; Lövbrand and Stripple 2015). The concepts developed differ in focus, but share the recognition of truth as a central device for governing, because it is by truth assertion that institutions govern (Glynos and Howarth 2007), that issues matter as policy issues (Yanow 1996; Stone 2002); and because truth subsequently legitimizes practices (Bevir 1999; Lorenzini and Tazzioli 2016), provides narration about how policy develops (Lejano and Leong 2012) and creates legitimate coalitions of actors (Braun 2015; Hajer 2005a).

These discursive lenses on truth production are important for understanding post-factual politics because they simultaneously unveil the other, and more fundamental, part of the lesson we can learn from Semmelweis's story: namely, that truth, while being negotiated, has been sometimes at odds with the governing elite, which has used subversion to stage the need to change and to revise the established path-dependencies. Critical policy inquiry needs to develop more subtle tools of analysis to understand this subversive play of truth. By addressing the negotiation, argumentation and presentation of truth, by turning scholarly attention to its socio-cultural interdependence, critical approaches have rendered the modern focus on rational and sound knowledge exposed to socio-political challenges. That governing elites might not always see the whole truth, by downplaying local or culturally and socially diverse knowledge, has been an important impetus for establishing the focus on this interdependence. Its background goes back to the emergence of the postmodern critique, ${ }^{9}$ as well as the critique of viewing facts aside from values, that have in manifold ways been addressed by social science since the 1960s. The postmodern critique of knowledge production sees the distinction between fact and value as a positivist illusion of neutral knowledge that needs to be fought. The narration of truth has been in the hands of sovereigns from dominant cultural and social backgrounds, which systematically downplayed the storytelling of those who do not have a voice in the debate. To hear these other stories has subsequently developed into a substantial political claim, having its origins in the 1960s, which highlighted in both academic and political discussions that Western societies cannot win the war on poverty and discrimination, that they cannot successfully fight for minority rights, unless the governing elites are persuaded to accept that there are truths to be told that so far have been silenced. 'The famous thread has been torn away, the one we thought would be so solid; Ariadne was abandoned earlier than has been presumed, and the whole history of Western thought is to be rewritten'10 (Foucault 1969a). 
In 1969, Michel Foucault, three years after the publication of The Order of Things, wrote in the French weekly Nouvel Observateur a review of Gilles Deleuze's book Différence et répétition, with the provocative title 'Ariadne Hanged Herself' (Foucault 1969a). Making waves in the philosophical community as an unorthodox way to destroy some of the fundamental philosophical works, Deleuze's book called for rewriting the classical philosophical understanding of subject, meaning and history. Fascinated by Deleuze's proposition, Foucault portrays this call through the famous myth of Ariadne, helping Theseus with a red woollen thread to find his way out of the Labyrinth, so that he can succeed in killing the Minotaur. In the myth, Ariadne helps him out of love, and waits for him. However, Foucault subverts the story: Ariadne is simply tired, bored and does not want to wait any longer for anything to happen. She hangs herself on the thread, thereby hijacking the previously common and well-known paths of what we have lived and what we have been living for. The thread is broken, Ariadne hangs herself, and Theseus will not find his way out: 'history of Western thought is to be rewritten' (ibid.) - that is the message of Deleuze's proposition that Foucault wants to transcend in our understanding of the knowledge hierarchy of modernity.

With the subverted story of Ariadne, Foucault wants us to understand that our identities have never been as solid as we might have thought. There has been a narration to make them solid and legitimate because this offered clear cultural and social borderlines. These borderlines come under attack through critical inquiry because these identities no longer appear as 'natural', but rather as socially, politically and culturally interdependent. Moreover, meanings and representations have always been dispersed. Western societies have been hiding this dispersion behind the curtain of a 'non-contradiction'. As Foucault argues, the contradiction has appeared right before our eyes: in the streets, in politics and in academic knowledge. The curtain of solid identities and straightforward narrations is ripped off:

The veil is torn: this veil is the image that thought had formed of itself and which allowed it to exist. It was believed, it was said: thought seemed to be good (proof: common sense, which gave it the right and duty to be used); thought seemed to be one (proof, common sense); it dispelled error, piling up grain by grain the harvest of true propositions (the beautiful pyramid, finally, of knowledge ....). (Foucault, ibid.) ${ }^{11}$

Foucault's fascination with Deleuze's proposal to go inside the production of thought and reveal how knowledge is made can be explained by his own approach. With his proposal to analyse historical events and power relations through discourses, Foucault challenged the positivist methods to show that history is made, and that we need to ask and analyse 
who makes it, and how (Foucault 1969b, 1976a). This is not the place to argue for the Foucauldian method, as many others have already done extensively elsewhere. ${ }^{12}$ The Foucauldian perspective toward the narration of events is an important reference to understand the larger background of postmodern critique establishing philosophical grounds for the discursive interdependence of truth and the subsequent need for new ways of analysing knowledge in social sciences. Other theoretical approaches have followed his proposal to re-narrate the Western world, which focus on the uncertainty and the slippery character of knowledge, as does for example Jacques Derrida, in his focus on the differences among the established significations (Derrida 1967) and the subsequent proposition to deconstruct these differences; or as does Jean-François Lyotard, in outlining the postmodern condition of the world surrounding us, thereby making legitimate multiple understanding of this world (Lyotard 1979), which is also partly reflected later in Zygmunt Bauman's notion of 'liquid modernity' (Bauman 2013).

Beginning with 1960s, the rapidly emerging social movements demanding more attention to and more rights for those who have been outside these Western narrations were performing this challenge of governing elites by articulating political claims as a fight against the narrations of the world that had been presented as the only legitimate truths (Worms 2018). In their effort to tell the truth of those who have been silenced, these movements reached beyond finding answers to specific political problems: they were in fact outlining the epistemological problem with truth-telling, which Foucault refers to with his subverted fable of Ariadne. This epistemological problem simultaneously gave rise to severe political consequences and, importantly for the focus of this book, affected the establishment of scientific knowledge as culturally ascendant. Battles over truth have thus subsequently been initiated in all social scientific disciplines to show that paying stronger attention to discursive registers, through which we label knowledge as 'relevant', 'scientific', 'sound' and 'rational', is a way to understand the power play behind the knowledge-making. Such knowledge has not always been 'good', as shown by some scientific achievements leading to catastrophes or even genocide; it has never been 'one', for it has mainly been hierarchical knowledge in our Western world, while other types of knowledge and knowledge-making have developed elsewhere; and it has often been 'wrong', because that is how scientific progress proceeds, for without correcting previous errors there would not have been any progress.

Epistemological battles inside the social sciences occurring in parallel to political calls for rewriting Western history are essential for understanding how the investigation of truth has been opening toward negotiation with 
politics and society. These battles expose for us the rage against the hierarchy of knowledge, and remind us of the current post-factual binary of factual and emotional. To begin with, the French semiologist Roland Barthes jeopardized literary critique by contesting the traditional and established interpretation of the French classics author Jean Racine (Barthes 1963). A Barthesian view on language subverted the theretofore accepted system of high and low literature (Barthes 1963). By focusing on myths that we use in our everyday lives for the narration of events and of ourselves, Barthes opened the door to a more dynamic use of metaphors to show that society as a whole - not only its knowledgeable elites - participate in the act of interpretation (Barthes 1972). The subsequent call for new methods in literary critique spurred interest in the act of interpretation as a socio-cultural and political enterprise, unveiling registers that hold interpretations of the surrounding world together, that make them true for actual social, political and cultural circles (Geertz 1973; see an overview of the works in Yanow 2006).

To investigate truth subsequently implied to investigate the particular language used to present truth. Linguistic methods, systematically following the principles of and the use of language through grammar structures and style rules, have slowly begun to propose conceptual grounds to understand that the words we use mean what we negotiate them to mean. Interaction, communication and the performative character of language are approaches that aim to go beyond the analysis of grammar and style. Emile Benveniste introduced the concept of 'intersubjectivity' (Benveniste 1966), showing consequences for the interpretation of meaning once we accept that all production and reproduction of meaning is intersubjective and thus constantly negotiated by those who use the language. Language is not only about meaning, but about the meaning that is shared, and this view has become the central analytical path to unveil the new boundary of language. By asserting that language is performative and creates deeds (Austin 1962), a systematic analysis of language has been initiated through the socio-political challenge that language both incorporates and is influenced by (Jakobson 1977; Ducrot 1972).

The epistemological call for new boundaries of language subsequently underpinned the greater call for new methods in social inquiry (LéviStrauss 1973; Goffman 1969 [1959]) that have laid the groundwork for the establishment of interpretive, and reflexive, social science (Meyer 1994; Turnbull 2004; Laclau 1996; Szerszynski 1999; Wagenaar 2011; Bruner 1990; Fay 1996). This call for new methods went hand in hand with the epistemological reflection of narrating historical and present events, and science has been also part of this call. The appeal of Thomas Kuhn (1962) was that - in a spirit close to what was at the same time described 
and criticized by Deleuze, Barthes and Foucault - he gave new impetus to follow the establishment of scientific knowledge. Borrowing the term 'paradigm' from linguistics, Kuhn reacted to the positivist idea that scientific knowledge is distinct from other kinds of knowledge, a notion that culminated during the Enlightenment and had been strengthened through both the industrial revolution and the rise of capitalist societies (as show in their conceptualizations of scienctific knowledge e.g. Porter 2009; and Nowotny 2015). By claiming that science has an internal dynamic and reveals itself to be an agonistic field, Kuhn broke a path for understanding scientific production as embedded within society, as being part of a paradigm. Kuhn's perspective of a paradigm opened the door to analyses of how science is made, by whom it is made, and with what norms it is supported.

However, Kuhn, although admitting that science does not exist in a vacuum, did not see any problem in the culturally supreme position of science, and thus did not propose any analysis of the socio-political interdependence of these norms, let alone question their existence. This exclusive relationship of scientific knowledge to the rest of the world has attributed cultural ascendency to science and, as such, science has been sustained as a primary custodian of truth in modern post-war governing through expertise and science advisory bodies. The incorporation of scientific evidence should ensure ongoing progress, and so the belief in science was at the same time a belief in a good and prosperous society. Although particular scientific discoveries came under attack during the 20th century, and although organized social movements - mainly in pharmacology, health and environment - have criticized science for making errors and creating victims, these movements have not questioned the overall legitimacy of scientific knowledge. As in the Semmelweis story, the rationality of science, together with its systematic inquiries and its path-dependencies, were seen as sufficient guarantees.

The rationality, neutrality and objectivity of science are cornerstones of this culturally supreme position of scientific knowledge throughout modern times. Semmelweis's story is thus not only relevant in the special context of 19th century medicine: similar stories about controversial science offering a happy ending through guarantees and regulatory frameworks inside science are part of the public image of science in the 20 th century as well. One of the most famous cases in modern medicine showing such a guarantee within scientific production and regulation was the blocked introduction of the German sedative Contergan Forte in the US drug market in the 1960s (see an analysis of the case in Carpenter 2014). Contergan was released in Europe in 1957 as a sleeping pill after undergoing laboratory and clinical tests as expected by German regulatory 
authorities. It was also given to pregnant women against morning sickness. Its great advantage was that it was not toxic, which reduced the risk of overdosing. Soon, Contergan became the best-selling sleeping pill and sedative in Europe. At about the same time, the first cases of malformed newborns appeared (Daemmrich 2002; Kuehn 2010; Quirke 2013). Some neurologists warned about the possible association with Contergan's use, but the drug manufacturer rejected those accusations. Contergan wanted to enter the US market in 1960, but Frances Kelsey-Oates, working in the US Food and Drug Administration (FDA), repeatedly refused to let the pill into the US market. Mainly, Kelsey-Oates was hesitant over the tests, which she did not find robust enough, especially as there was not enough information about the impact of long-term use. She also repeatedly pointed to doubts about the safety of the drug, as more and more children in Europe were being born with deformed or missing limbs. In November 1961, paediatrician Widukind Lenz confirmed the awful hypothesis that this phenomenon resulted from the use of Contergan forte during pregnancy. The drug was withdrawn, and civil and criminal trials of the company followed. In the United States, however, Contergan's affair had almost no victims, since - thanks to Kelsey-Oates's engagement - the drug was never released. Kelsey-Oates was celebrated for having averted the tragedy that affected thousands of children in the world, and she is still now portrayed as the expert who saved US children from this affliction. Even more essential for the present discussion, however, is that she was backed strongly by the institution designed both to support and to regulate science: the US Food and Drug Administration. The FDA helped KelseyOates to resist the pressure of the US pharmaceutical lobby. As a wider consequence of the Contergan affair, the world drug market was tightened, experiments were made more rigorous, and to investigate side-effects and risks related to drug use has become an intrinsic part of pharmaceutic research (Webster et al. 2011; Haddad et al. 2013). Science has progressed, and succeeded in regulating itself.

While showing a positive image of US regulatory agencies, KelseyOates's story is also part of the narratives portraying scientists as being gifted with almost supernatural ability to understand new dimensions of the world around us, and to guide societies, and governments, to act. This narrative is powerful and encompasses different historical contexts. When scientists have been in conflict with the prevailing morality, they have not been intimidated by cultural prejudices or religious beliefs, but have defended their truth, and their method to achieve that truth. When there has been institutional pressure put on them, scientists have not succumbed but have held to their scientific methods. This notion of science has strengthened its public image of neutrality as a guarantee of truth, and has 
sustained rationality as an asset for the societal progress of modern societies. Subsequently, the origin of the modern notion of scientific knowledge has developed in its opposition to personal experience, belief or culture. When a belief was present in the development of scientific discovery, it was not a disturbing belief recalling socio-political embedding, but an inner belief - again, almost supernatural - of a scientist prepared to follow their path whatever it took. The systematic pursuit of facts and evidence implicitly supposed a division between rational experts who are trained to carry out this pursuit, and the irrational public who believe and trust the results of this pursuit without necessarily being involved in it.

Such recurring portrayal of culturally ascendant science that is selfsufficient in guiding societal progress is an important context of the postfactual times. In 2017, 'the veil is torn' again, as Foucault suggested back in 1969 , but this time it is not science and academia protesting against political elites silencing minorities' truth, but the angry public protesting against science that has been claiming to represent truth. The rage is still analogical to what Foucault described in 1969: in the name of the personal experiences and beliefs of the public - in the name of 'the people' - scientific knowledge, which had seemed so solid and undefeatable, is now under attack. It is attacked for not really having hard evidence at hand (yet) on some scientific issues (such as sudden infant death syndrome for example). Science's capacity to detect and repair errors, that used to be universally recognized, is challenged by the frequent advent of scientific errors in modern times, such as the asbestos controversy (Gilbert and Henry 2009) or the already evoked Contergan forte tragedy that was silenced for so many years in Western German medical discourse (Kirk 1999). On this basis, many now contest science's role in leading societies to a better future (Gauchat 2015). All these attacks expose in their argumentation that scientific method and scientific inquiry have, through their public performance, created a cultural reference from which science denial could develop into a legitimate cultural position against an elite - a scientific elite this time - that does not care about normal people's experiences, and that is just preoccupied with facts and truth without respect for the culture so dear to us.

This is what creates the contours of the alleged attack on truth: although scientists have facts on their side, asking those in power to 'bow down to the facts' (HE 13 February 2017), government officials do not care about facts, and neither does the public supporting the Trump administration. It is even the case that the opposing side turns scientists' emphasis on facts into a negative, portraying it as an obsession. The attacks on truth and science during 2017 are not only about a particular political establishment and governing elites trying to control the production of science; this control goes along with a public that applauds such regulations because 
it fears scientists, or simply dislikes them because it sees them as arrogant know-alls.

The intellectual malaise expressed in both scientific and political discussions throughout 2017 about these attacks on truth initially seemed to play into the hands of those scholars who had been claiming for some time that the critical inquiry into knowledge production had 'run out of steam'. The boundaries seemed to be clear when this battle on truth began: while the positivist illusion of neutral facts - the crucial argument of critical inquiry that since the 1960s has been questioning hierarchies of the Western world - seemed to be overcome by the inclusion of alternative sources of knowledge, and by the possibility of contesting the hegemonic knowledge, it was precisely this criticism that all facts have value and that all opinions have to be heard that seems now to legitimize the post-factual situation where 'emotions matter more than facts' (d'Ancona 2017). All these approaches therefore opened up the possibility of denying academic knowledge and of claiming science as a 'super sliding nonsense' (Sykes 2017). Some scholars have reacted to this shift with investigation of the value orientation of critical discourses around truth (Shore 2017), or with an ideological analysis of truth production (Van Dyk 2017). Some portray the spread of postfactualism as an attack on the liberal-left hegemony (Hopkin and Rosamond 2017) that has failed to understand its own limitations (Krastev 2014). The underlying argument of these analyses is that the liberal-left hegemony was never really interested in the 'left' agenda, but rather in prioritizing liberal individuals, which is why it complied little by little with the neoliberal economy. Further, it left behind people who did not profit from scientific progress (Beck 2015), but have become even more exploitable. The consequence of these circumstances is that to argue for the turn away from and against scientific knowledge appears as a legitimate political cum cultural position. In the following section, I therefore discuss the larger political consequences of the democratization of scientific knowledge to develop the argument that critical inquiry has eventually become a tool of post-factual discourse; not because it accepted other sources of knowledge, but because it never challenged the way in which references to emotions have been used to delegitimize knowledge and the actors who have spoken out.

\section{THE BROKEN PROMISE OF PARTICIPATORY DEMOCRACY}

People are rational, can process information intelligently and independently, know the truth when they see it, do not need strong leaders, can engage in criticism, and easily coordinate their own society. Law is not an external 
mechanism that coerces people but an expression of their innate rationality, mediating between truth and mundane events. (Alexander 2006a, 60)

The Western world seemed to be civilized and democratic. The main ambition of modernity seemed to be achieved: outward-looking individuals can express their political opinions freely, and they can alter political decisions through protest if they disagree with the decisions of those who govern. Contesting knowledge has been identified as inherent to the liberal democratic order (Seidman 2016; Brown 2003; Kellner 2014; Cronin and De Greiff 2015) and, in that context, the belief in and cultivation of the democratic power of civil society has been praised as the consequence of the post-1968 development across the Western world to create a socio-political background of modern democracies. Academic scholarship in social science has sided with these developments, for it has responded to civil right protests, student unrest, and the beginning of critical debates around science by devoting substantial interest to participation and by studying the role of public(s) in politics and in science. The works of John Dewey (2007) and Walter Lippmann (2009), as well as some classical works asserting the democratic role of debate (Habermas 1990; Arendt 1972; Sennett 1976; Arendt 2003) see the public as in need of democratization and empowerment, and prepared the ground for a distinct approach to the public sphere. Developing a concept of the public sphere based on dialogue and deliberation, Jürgen Habermas (1981) offered a theoretical framework to sustain this post-1968 critique of technocratic governing (see also in Torgerson 2010) in a coherent theoretical and methodological approach that later built a substantial canon of critical policy studies. The Habermasian influence on policy studies supposed a reign of reason coming from an emancipated and educated public. Studying these processes of informing, debating and governing was linked to a promise (going beyond critical policy studies) that scholars will be able to propose appropriate democratizing frameworks to deal with disagreement and contest (Gutmann and Thompson 1998; Mercier and Landemore 2012). To highlight the democratic capacity of the public, policy studies constructed them as 'deliberative' citizens (Dryzek 2005; Fischer 2009b) who can be engaged and empowered to act and to debate in civilized ways to achieve mutual acceptance (Fung 2006; Fung and Wright 2003). ${ }^{13}$

The criteria of acceptance and legitimacy of particular sorts of knowledge in a democratic debate have been carefully studied within the democratization of scientific knowledge, where the coproduction of knowledge has shaped the establishment of the scholarship of science and technology studies (STS) as a distinguished scholarly path. The 
promised democratization of science raised prominent debates beyond the Anglo-American debate, to spark the discussion around legitimacy and contestation of expert knowledge among German scholarship in social science (Beck 1986; Braun and Kropp 2010; Gottweis 1998; Voß 2016) as well as in French political science and sociology (Borraz 2008; Callon et al. 2001; Gilbert and Henry 2009; Barnes et al. 1996; Lascoumes and Le Galès 2005). All these studies have anticipated a broader turn to participative models of governing that affect public interventions and interactions between what used to be distinguished as 'experts' and 'lay persons'. The participatory turn has subsequently influenced public debates on science (Epstein 1996; Prainsack 2014; Wynne 2001). Which knowledge counts as the relevant one, and why it counts as the relevant knowledge, was henceforth part of the analysis of the diverse publics and their engagement in the context of scientific debates (Brown and Mike 2002; Irwin 1995; Harding 2008; Novas and Rose 2000; Rose 2001).

Seeing knowledge as a dynamic and collective enterprise was essential in establishing STS approaches as a gateway to problematize science, and to follow analytically its regulation and its socio-political and cultural embedding. Since the late 1980s, studies highlighting the importance of the public understanding of science have started a scholarly tradition to identify major concerns in the interaction between science and society (see, especially, Thomas and Durant 1987; Stilgoe et al. 2014). Analyses of the ambiguity of scientific knowledge (Wynne 2010), that give impetus to public defences and contestations of scientific knowledge (Jasanoff 2003b, 2011), were the most prominent of these works to raise the issue of public accountability of science and experts, and the importance of this accountability for politics. In their critique of a univocal sense of rationality, objectivity and validity in science, and in their critique of Kuhn's unreflexive manner of addressing norms in science (Callon and Latour 2013; Fuller 2007), STS scholarship has opened up analytical investigation to power relationships inside knowledge production, and to the way knowledge creates publics that are seen as either legitimate or illegitimate to speak up in public debates around science (Collins and Evans 2008).

While promoting the necessity of the public understanding of science, STS approaches have implicitly conceived dynamic knowledge-making in science as emancipating, outward-looking and thus leading to a democratic and prosperous future. Although these paths - in both policy studies and STS - led to recognizing democratic societies as participatory, with a clear focus on deliberation (Dryzek 2012; Sass and Dryzek 2013), and although public engagement activities have been spread across scientific, technological and political discussions (as shown by analyses of public attitudes toward technological progresse and science; Bogner and Torgersen 
2015; Felt and Fochler 2010; Priest 2013; Irwin 2001), these efforts now seem to be weakening in the light of post-factualism.

The belief has been developed through studying public debates and engagements that by increasing the public understanding of science, and by making civil society more involved in the decision-making process of political institutions, political elites will be scrutinized more systematically and thus be prevented from lying and from using half-truths. Informing the lay public about the expertise supporting political actions, to make them part of that expertise, has prepared the ground for this scholarship that reaches beyond these two disciplines and has established a distinguished interest in public engagement and civil society in all social scientific disciplines. The promise was that, through actions as these, the public will be able to make informed decisions, will cultivate public discussion, and divided societies and political tensions will be prevented. Citizens will recognize the truth when they see it, as we read in the introductory epigraph from Alexander's civil sphere theory (Alexander 2006a) at the beginning of this section.

What went wrong? How can those who had been preaching the democratization of knowledge and open public debates be blamed for opening the door to fact-deniers? It is important to understand that the critical discourses to subvert 'truth' that were designed to challenge and change the established power relationships in the 1960s are now sought to be replaced by discourses that aim, on the contrary, to preserve an order of things that does not want to include other - especially minority - voices. That critique of knowledge no longer contributes to democratization and this important difference must be discerned. To understand how the post-factual shift toward disbelief in science and toward legitimizing the use of inaccuracies has occurred, and how it turned against the experts, let us look more carefully at how, in their effort to promote public debates on factual knowledge, modern governments have constructed participatory and deliberative discourses as rationalizing efforts, and enabled discursive strategies to delegitimize opponents and to exclude perspectives on the basis of the emotional content of the opinions and stakes presented during these debates. This had an effect on the view of science and its public role in the defence of truth during the protests in the United States in the aftermath of Trump's election. More specifically, by making the case for the democratization of knowledge, the discussion around public debates and deliberation seems to have downplayed the underlying value registers that hold the rules of such democratization together. Related to that, patterns of discussing and arguing have been analysed as universalizing structures, aside from culturally charged patterns. Cultural codes that enable and constrain particular discursive registers, as well as particular rhetorical 
devices to reference emotions in these debates, have not been given enough analytical attention. This has sustained and rendered implicit the binary opposition of factual and emotional in knowledge.

Rationalizing public debates, using rationalizing discursive registers, responded well to the cultural paradigm of post-industrial Western societies. The overall discursive register of these debate settings was coproduced by the power structures of post-World War II technologically rising societies, that played into the technocratic design and systematization of needs and concerns (Alexander 2013, 2006a; Beck 1986). This paradigm has been coproduced by the idolatry of neutral knowledge, value-free, aiming at the exchange of facts that will create enough context and circumstance to achieve mutual understanding. Neutral knowledge has at the same time been seen as the essential quality of science, designed subsequently as a rational and non-partisan enterprise. This characteristic of scientific knowledge can also be seen in the critique which appeared in the public understanding of science, alerting that the alleged neutral scientific expertise was being alienated from the lives of ordinary citizens (Wynne 2001, 2006; Quet 2014), lacking self-reflexivity (Wynne 2006) as well as a continuous forum for addressing citizen concerns. This also created the basis for the binary of factual knowledge generated by science and the emotions felt by the public. Subsequently, concepts advancing deliberation and dialogue, albeit promoting participation of the public in the civil debate - have at the same time conceived the public as irrational, and that believes and trusts in the results of the expert inquiry that the public can now transparently - and democratically - follow. Scholarship on deliberation argued for 'the mild voice of reason' (Bessette 1997), the 'democratic reason' (Landemore 2012) as necessary tools for successful deliberation and searched for answers to deliberation conflicts in the field of political psychology (Mercier and Landemore 2012). This limited the investigation of the discursive registers of emotions, because political psychology framed emotions primarily as urges motivating actions (Jasper 2011, 2008; Polletta and Jasper 2001), rather as language practices organizing the knowledge that is presented in these deliberations.. This was a part of the paradigm supporting the development of policy studies as a systematic inquiry of knowledge, publics and government. Laswell, to give one example that has been important for setting up policy studies, addressed the emotional through a suggestion of bringing psychoanalysis into the study of policies, which would raise the consciousness of the inexperienced public through adequate procedures (Lasswell 1927, 1933).

One might argue that at the heart of the critical inquiry in policy studies has been a call for new methods to analyse public debates and policy-making, which aimed at delving into the common understandings 
of values and beliefs through which demands for civil repairs appear in the public sphere. And that was successful in proposing an analysis of values and beliefs. Making the critique of the fact-value dichotomy its crucial asset, critical inquiry has indeed offered a counterpart to the strong empiricist tradition, which has been used by the positivist tradition of social science. This appeared initially as an endeavour that challenges the paradigmatic framing of political rationality, for the assumption was that the critical debate about values can be institutionalized through analysis of the processes of data collection, information-gathering and evidence production. The subsequent study of socio-political interdependence of knowledge among experts and publics, however, which critical policy studies advanced and expanded from this assumption, has continued to employ the paradigmatic framing of rationality. On the level of observing policy processes, 'misunderstandings' have been opposed to 'mutual consensus' and 'compromise'. 'Failures' of policies were also treated as pathologies of policy processes, opposed to rational elaboration of propositions and designs (see the critique of this view in Zittoun 2015). On the level of public acknowledgment and citizens, scholarly works - albeit recognizing specific problems in the interactions among actors concerning the ambivalence of the knowledge around a policy, thereby affecting who the relevant actors are to play a role in the policy issue (Gottweis 2003, 2006; Lejano and Leong 2012; Zittoun 2014) - have attempted to offer a critique to the paradigmatic setting by focusing on the discursive registers used to formulate or criticize policy agendas (Hajer 1993; Fischer and Forester 1993; Wagenaar 2011). Without referring to emotions that coproduce, legitimize or delegitimize these discourses, these approaches have not challenged the paradigmatic framing of rational policy procedures.

The intensified focus on language and its interpretation of what policies mean (Yanow 1996) has further aimed at offering a more subtle analytical apparatus of the language used in deliberation and everyday politics, which has been seen as a way to analyse the different types of language used in political debates (Fischer and Forester 1993; Fischer 2003). By comparing different sorts of knowledge - such as truth claims, statistical data, individual assumptions, and scientific hypotheses and narratives - and by investigating how this knowledge is used, and by whom it is used, scholars have unveiled how rhetorical and argumentative links between these sorts of knowledge are established (Fischer and Gottweis 2012; Fischer and Forester 1993). Here the promise has been that such analytical endeavours can explain why some truth claims or assumptions are more likely to garner support, while others are rejected. Key analytical concepts of critical policy studies such as arguments, narratives and discourses have, however, developed into rationalizing 
structures as well, for they implicitly undermined the role of emotions in these discursive procedures and restricted the study of emotions to contentious issues (Gottweis and Prainsack 2006; Fischer 2009a) which are emotionally loaded because they are linked to emotional spheres of our lives (Orsini and Wiebe 2014) or negotiations conflicts (Verhoeven and Duyvendak 2016). Some approaches, focusing on emotions, aimed at conceiving emotions as opposed to discourses: they proposed analysing feelings and body language in policy work (Anderson 2017), as well as suggesting that a distinction be made between affective and meaningoriented sides of human interactions (Ducey 2007), thereby conceiving of emotions as antithetical to language structures and the interpretation of meaning'(Clough and Halley 2007; Gregg and Seigworth 2010). Related to that, to view interpretation as a rationalizing structure has also been inherent in the poststructuralist approach to language and interpretation, which defines emotions as a pre-stage of meaning structures, as can be seen in the work on the role of fantasies (Glynos 2008) or psychoanalysis (Stavrakakis 2007, 2017) in understanding politics. Stavrakakis speaks about 'sophisticated affects', which implies that, in order to become meaningful, an affect needs to pass through the structure of language that 'sophisticates' it (Stavrakakis 2009, 9).

That emotions might not necessarily be linked to conflicts and negotiation breakdowns only, that they are not limited to physical sensations and behaviours, that there is a discursive dimension of how we make emotions meaningful, and that this dimension affects socio-political embedding of knowledge, have all been missing from all of these critical discussions. Cultural codes and socio-political embedding were mentioned and analysed in debates on publics (Dewey 2007), as aspects and framings that create difficult dynamics, and can render participatory models and empowerment strategies difficult because they are in conflict with cultural path-dependencies (Fischer 2009a). But these cultural codes were not linked to argumentative procedures and discursive registers studied by these works. Although some scholars such as Thompson and Hoggett (2001; see also Clarke et al. 2006) and van Stokkom (2005) for social policies, and Newman (2012) for public participation, asserted that emotions are part of knowledge-making, and that they create cultural and social identities (Hunter 2015, 2003; Jupp et al. 2016), they have not analysed the codes and narratives, the language procedures, of emotion's role in knowledge-making. Among those analyses that focused on procedures of knowledge-making, some did speak about identity-building as a necessary basis for political action (Stone 2002), and about the sharing of knowledge across publics (Voß and Freeman 2016) and the building of actor networks through performance (Hajer 2005a), all phenomena linked to emotions; 
but these studies have not focused on emotions in these creations, ways of sharing and performances.

All these approaches aspired with their approach to knowledge-making to a more inclusive world of political debate, and they have been very successful in offering arguments for such inclusiveness. However, they disguised that rational pursuit of knowledge and its analysis is not a matter of truth: rather, it is part of the cultural ascendency of the truth. Although there was an implicit normative framing of how the plurality of knowledge is feeding into the political debate, they dominantly focused on knowledge (production), argumentation and communication. An implicit - and perhaps unintended - hierarchy slipped through: knowledge stayed a solely rational enterprise, used on purpose to evacuate the wild and chaotic 'emotions'. At the same time, this implicit hierarchy has also prevented questioning or analysing the circumstance that the sceptre of truth is held exclusively by established expertise and science. By opening expertise to discussion, they were not prepared for a situation where the framing of the discussion could become questioned. They have been surprised that now they will have to come up with argumentation on why the sceptre is and should stay in the hands of science.

Hence, investigating the criteria of scientific expertise, and the parameters of why relevant knowledge is seen as such - while responding to the inquiry of the socio-political interdependence of knowledge - alerts interest in the cultural ascendency of scientific knowledge and in the concrete codes, narratives and other rhetorical devices that have held the discursive register of the alleged neutrality of expertise alive, and still powerful, over the last 50 years. It is necessary to look toward the discursive registers that produce and sustain this cultural ascendency. The interest in these discursive registers can offer an analytical perspective with which we can still admit that things can be context-dependent, and especially emotionally loaded, without playing into the populist endorsements of inaccuracies and the marginalization of science.

The opposition of science and emotions has given rise to incorporating a culture of scientific truth as the cornerstone of the evidence-based rationality of modern democracies, and as such it has engendered the binary of factual and emotional, which has placed emotions in opposition to knowledge-making (Alexander 2006a). Although some references to the emotional have been attributed to the role of productive and civil passions as part of the rationality of knowledge-making, they have not been referenced as 'emotions'; instead, they were productive 'passions' or understandable 'individual attitudes'. This has sustained the word 'emotion' as an argumentative scapegoat for both scientific and political discussions (as argued by feminist epistemology; see Ahmed 2004; Harding 2008; 
Sauer 2001) and has created an argumentative arena in which evoking the emotional aspects of knowledge has been disregarded and dismissed as distracting and destructive for the debate.

Overlooked or despised by critical inquiry, the boundary between emotions and knowledge could then well grow into a tool of post-factualism. The binary of factual and emotional has twisted the language of expertise and science, and the mere reference to emotions without any further contextualization would not allow for distinguishing particular values, beliefs and interests that would be informed by particular references to emotions. Without a diversified language of emotions at hand, historical accounts of scientists paint a picture of rationality winning the battle of truth all over again. In that way, the rationality of science has been used as a curtain to hide the impossibility of offering a diversified language on emotions that allows us to understand how knowledge is not only socio-politically but also emotionally embedded, involving irritating moments, moments of surprise, anxiety, responsibility or hope.

Accepting the boundary of knowledge and emotions in science on both sides of scientific conflicts means going beyond the famous fact-value dichotomy to see how the modern overlooking of the emotional aspects of the negotiation of truth leads to insufficient explanations of how scientific discoveries are acknowledged and established. It might be time to accept that science has developed a culture of emotions that needs to be reconsidered in the light of the current attacks on truth. It might be that the battle about truth needs to offer something beyond the mere emphasis on fact and truth, for this emphasis is the scapegoat the other side is waiting for in order to attack it. Considering the value dimensions of knowledge-making can help us to see what interests and values might be hidden behind science's objectivity and neutrality. At the same time, it can help us to offer a diversified picture of protests against established science and partisanship.

By insisting on the neutral and objective character of scientific enterprise, modernity has created a discursive register of 'rational' of 'factual' that is opposed to emotions. It has, at the same time, made opaque that some emotions are, and should be, part of those factual registers. Through this opacity, it has offered the use of emotions to all those who want to challenge factual knowledge: not to enhance it, such as Semmelweis, but to undermine it, or eventually to destroy it. Those who make emotional statements are staged as being against the established elite and knowledge order, and this might brand them as siding with the intense experiences of citizens and opposing the distant elites. This challenge of the established elite and knowledge order might stage them as having truth on their side, because, as the classics in epistemology of sociology of scientific knowledge have taught us, criticism is disruptive and criticism is disruptive and 
undermining traditions and established myths is a killjoy (Latour 2004). We therefore need to unpack this disruptive moment of truth production in order to distinguish science denial and the undermining of science from critical inquiry into truth production (Tony Judt elegantly terms it 'the seduction of postmodernism'; Judt 2015, 1992). Because the discourse of disbelief in science misuses vexatious knowledge and stretches its partisanship ad absurdum, it is necessary to analyse these two important emotional dynamics of truth production. Both vexatious knowledge and partisanship help us to understand how truth is being coproduced, and negotiation through emotional appeals to facts, and how the binary of factual knowledge and emotions undermines truth instead of making it more solid.

The analysis that follows in the next two chapters thus offers a closer analysis of vexatious knowledge and partisanship as two important dimensions of this emotional dynamic of truth production. It shows that public defence of science represents the binary of factual knowledge and emotions, and that it creates a cultural divide between those who know the truth and those who either do not know it or do not want to know it, because it is at odds with what they stand for or what they take profit from. The analysis of the 2017 protests shows that the public defence of science must learn from Semmelweis. It is not that cautiousness and rationality has returned, but that emotionality in science needs to be rehabilitated: it needs to open up the analysis toward the discursive registers referencing emotions in order to distinguish between cautiousness and disregard, to distinguish between critique and conspiracy, to distinguish between necessary partisanship and instrumentalizing science for personal gain.

\section{NOTES}

1. One of the march organizers, Caroline Weinberg, on the radio show Science Friday.

2. https://www.vox.com/2018/5/4/17318932/dr-oz-trump-council-sports-fitness-nutrition (accessed 7 May 2018).

3. http://www.politifact.com/truth-o-meter/statements/2017/jan/21/sean-spicer/trump-hadbiggest-inaugural-crowd-ever-metrics-don/ (accessed 31 July 2018).

4. https://unfccc.int/process-and-meetings/the-paris-agreement/the-paris-agreement (accessed 3 July 2018).

5. https://www.washingtonpost.com/graphics/politics/trump-claims-database/?utm_term=. cc933652d40c\&wpisrc $=$ nl_evening\&wpmm $=1$.

6. See also the self-description by the March for Science organizers at https://www.march forscience.com/our-history (accessed 30 December 2017).

7. https://thebaffler.com/salvos/degrasse-tyson-kriss-atheists.

8. As often portrayed in monographs narrating the life and work of Ignaz Semmelweis (Nuland 2006; Benedek 1983; Wyder 1906; Semmelweis 1905; Flamm and Aspöck 1999).

9. The book uses the term 'postmodern' in order to capture the debate beyond political science and to reflect the larger extent of the meaning-oriented analysis to social 
analysis. Also, the postmodern condition is more familiar to audiences outside of poststructuralism and deconstruction; 'postmodern' is also more frequently used to reflect meaning-oriented analysis in international debates.

10. 'Le fil célèbre a été rompu, lui qu'on pensait si solide; Ariane a été abandonnée un temps plus tôt qu'on ne le croyait: et toute l'histoire de la pensée occidentale est à récrire' (translation by the author).

11. 'Le voile se déchire: ce voile, c'est l'image que la pensée s'était formée d'elle-même et qui lui permettait de supporter sa propre dureté. On croyait, on disait: la pensée est bonne (à preuve: le bon sens, dont elle a droit et devoir de faire usage); la pensée est une (à preuve, le sens commun); elle dissipe l'erreur, en entassant grain par grain la moisson des propositions vraies (la belle pyramide, finalement, du savoir ....)' (translation by the author).

12. Foucauldian thinking has been abundantly discussed and addressed in critical streams of political science and sociology (Howarth 2010; Lövbrand and Stripple 2015; Luke 2015; Sarasin 1999; Diaz-Bone 2006; Keller 2005; Dean 2010; Lemke 2011; Foucault et al. 2001; Nettleton 2000; Rabinow 1991; Lorenzini and Tazzioli 2016).

13. Chantal Mouffe's idea of agonism as a stance against deliberative procedures emerged as a counter-indication to these debates (Mouffe 2000, 2005), but her critique did not focus on concrete knowledge-making procedures in particular phases of policy process, but focused on the overall framing of political rationality. 